Михайленко В.В., Зіменков Д.К., Святненко В.А., Трубіцін К.В., Чарняк О.С.

\title{
ДОСЛІДЖЕННЯ ЕЛЕКТРОМАГНІТНИХ ПРОЦЕСІВ У ПЕРЕТВОРЮВАЧІ 3 ДЕСЯТИЗОННИМ РЕГУЛЮВАННЯМ НАПРУГИ І ЕЛЕКТРОМЕХАНІЧНИМ НАВАНТАЖЕННЯМ
}

Анотащуія: У статті проведено аналіз електромагнітних процесів в електричних колах 3 напівпровідниковими комутаторами. Створено математичну модель дванадцятипульсного напівпровідникового перетворювача 3 десятизонним регулюванням вихідної напруги для аналізу електромагнітних процесів у напівпровідникових перетворювачах 3 широтноімпульсним регулюванням. Наведено графіки, що відображають електромагнітні процеси у електричних колах.

Ключові слова: напівпровідниковий перетворювач, десятизонне регулювання напруги, електромагнітні процеси.

\section{Вступ}

Перетворення електричної енергії,дозволяє використовувати в перетворювальних установках ланку високої частоти з частотою переключення вентилів значно більшої від частоти змінної напруги промислової мережі [1-4]. У роботах [1-4] показана доцільність використання структур перетворювачів частоти (ПЧ) 3 однократною модуляцією при побудові систем вторинного електропостачання для комплексів діагностики електромеханічних пристроїв із різноманітним видом вхідної енергії. У даній роботі проводиться аналіз структури ПЧ для електромеханічних комплексів із широтно-імпульсним регулюванням (ШІР) постійної напруги при десятизонному керуванні. Широке використання напівпровідникових перетворювачів у електричних колах сучасних перетворювачів параметрів електроенергії значно ускладнюються задачі аналізу електромагнітних процесів. Найбільші ускладнення виникають при необхідності моделювання усталених і перехідних процесів у розгалужених колах змінної структури, в ланках з реактивними елементами якої виникають синусоїдні, постійні та імпульсні напруги. У даній роботі проводиться аналіз аспекту використання тієї ж структури напівпровідникових перетворювачів (НПП) в якості ланки високої частоти, що стосується побудови й аналізу перетворювачів для електромеханічних комплексів із широтно-імпульсним регулюванням (ШІР) постійної напруги при десятизонному керуванні.

Метою роботи $є$ створення математичної моделі напівпровідниковими перетворювачами з електромеханічним навантаженням вихідної напруги.

(c) Михайленко В.В., Зіменков Д.К., Святненко В.А., Трубіцін К.В., Чарняк О.С. 


\section{Аналіз електромагнітних процесів}

У данній роботі використано метод багатопараметричних модулюючих функцій [2], який передбачає попереднє представлення алгоритмічного рівняння перетворювача. При цьому прийнято такі припущення: вхідна енергетична мережа симетрична і ії внутрішній опір дорівнює нулю, транзистори і діоди інвертора випрямленої напруги (IBH) представляються ідеальними ключами, узгоджувальні трансформатори в кожній з зон регулювання вихідної напруги не мають втрат, а навантаження перетворювача має еквівалентний активно-індуктивний характер.

Узагальнена структурна схема перетворювача показана на рисунку. 1. На структурній схемі позначені: $\mathrm{CM} A B, \mathrm{CM} B C, \mathrm{CMCA}$ - силові модулятори (СМ) лінійних $\mathrm{AB}, \mathrm{BC}$ і СА відповідно, $\mathrm{BB}$ - високочастотний випрямляч, $\mathrm{D}$ - двигун постійного струму. Сукупність СМ, підключених до енергетичної мережі паралельно і з'єднаних по виходу послідовно, представляє собою ланку високої частоти перетворювача. Кожний з блоків СМ має у своєму складі випрямлячі та інвертори, навантажених на узгоджувальні трансформатори.

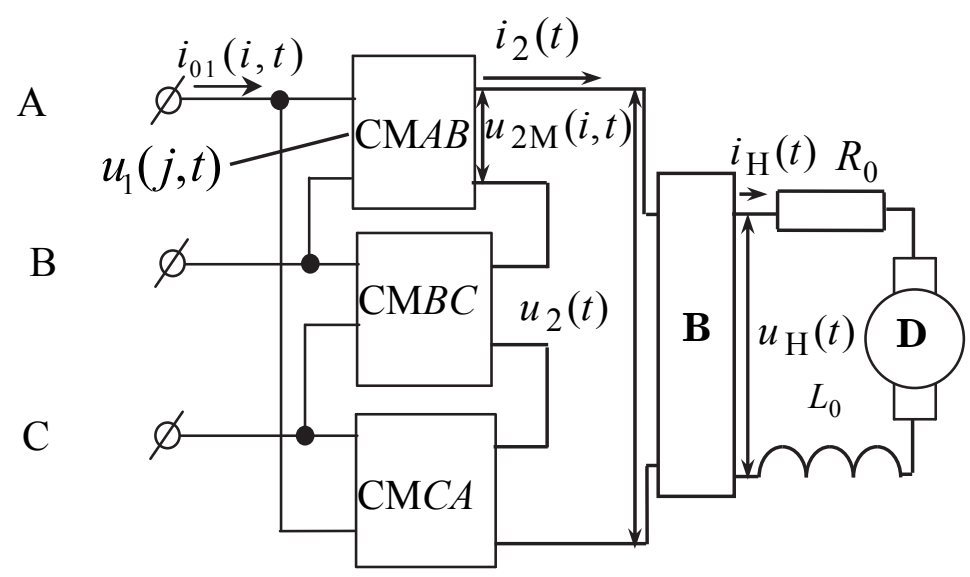

Puc. 1. Структурна схема перетворювача

Таким чином кожен СМ має в своєму складі $N$ IBH, де $N$ - це число інверторів. Створення математичної моделі перетворювача передбачає розробку математичного забезпечення, спроможного провести аналіз відносно енергії, яка генерується, з урахуванням навантаження, енергії, яка споживається, а також енергії, яка перетворюється в окремих ланках і в окремими елементами.

Дослідження техніко-економічних показників різного виду виконавчих елементів слідкуючих систем на основі високомоментних двигунів постійного струму (ДПС) серій 2 Па ПВ і трифазних асинхронних двигунів серії $4 \mathrm{~A}$, які випускаються промисловістю серійно [4], показують, що за умови однакових показників за масою та габаритами в діапазоні потужностей від 100 Вт до 500 кВт, у слідкуючих системах доцільніше використовувати ДПС. 
У роботі прийняті такі припущення: вхідна енергетична мережа симетрична $\mathrm{i}$ iї внутрішній опір дорівнює нулю, транзистори і діоди інверторів випрямленої напруги (IBH) представляються ідеальними ключами, узгоджувальні трансформатори в кожній з зон регулювання вихідної напруги не мають втрат.

Проведення системного аналізу електромагнітних процесів у модуляційному НПП з багатозонним регулюванням вихідної напруги з навантаженням у вигляді ДПС з послідовним збудженням, з урахуванням таких ознак системного підходу до аналізу [4], як цілісність та вплив під час іiі руху зовнішніх і внутрішніх факторів.

Напругу на навантаженні НПП знаходимо з виразу виду

$$
u_{\mathrm{H}}(t)=\frac{1}{k_{\mathrm{T}}} i_{\mathrm{H}_{k}}(t) \sum_{j=1}^{3} \sum_{n=1}^{N=10} u_{1}(t) \psi_{\mathrm{B}}(j, t) \psi(n, N, t) \psi_{\mathrm{BB}}(t),
$$

де $u_{1}(j, t)$ - миттеві значення лінійних напруг мережі, $\psi_{\mathrm{B}}(j, t)$ - функції прямокутного синуса, що співпадають за часом з положенням відповідних лінійних напруг, $n=$ $1,2, \cdots, N=10$ - номери зон регулювання; $\psi(n, N, t)$ - множина еквівалентних модулюючих впливів $j-\mathrm{x}$ інверторів СМ; $\psi_{\mathrm{BB}}(t)$ - функція прямокутного синуса, що співпадає за часом з положенням напруги $u_{2}(t) ; k_{\mathrm{T}}$ - коефіцієнт трансформації.

ДПС, що задає вихідний струм НПП, описується системою алгебраїчних рівнянь [4]

$$
=\left(\begin{array}{c}
\left(\begin{array}{c}
i_{\mathrm{H}_{k+1}}(t) \\
n_{k+1}(t)
\end{array}\right)= \\
i_{\mathrm{H}_{k}}(t)+\frac{2\left(c(t)-\varepsilon_{c h}\right)}{a_{1}}-\frac{2 \varepsilon_{a}}{a_{1}} i_{\mathrm{H}_{k}}(t)-\frac{2}{a_{1}} n_{k}(t) i_{\mathrm{H}_{k}}(t)-\frac{2}{a_{1} a_{3}} i_{\mathrm{H}_{k}}^{3}(t) \\
4\left(c(t)-\varepsilon_{c h}\right) i_{\mathrm{H}_{k}}(t) \\
a_{1} a_{3}(t)+\frac{2 \varepsilon_{\mathrm{M}}}{a_{3}} n_{k}(t)+\frac{2}{a_{3}} i_{\mathrm{H}_{k}}^{2}(t)-\frac{2}{a_{1} a_{3}} i_{\mathrm{H}_{k}}^{3}(t) n_{k}(t)-\frac{2 \varepsilon_{\mathrm{M} 0}}{a_{3}}
\end{array}\right),
$$

де: $i_{\mathrm{H}_{k}}(t), i_{\mathrm{H}_{k+1}}(t), n_{k}(t), n_{k+1}(t)$ - струм якоря та кутова швидкість обертання ДПС на $k$-ому та в $k+1$-ому інтервалі відповідно; $\varepsilon_{c h}, \varepsilon_{a}-$ відносні падіння напруги на щітках і обмотці якоря; $\varepsilon_{\mathrm{M}}, \varepsilon_{\mathrm{M} 0}-$ відносні моменти опору на валу; $c(t)=\frac{u_{\mathrm{H}}(t)}{E}-$ відносне значення напруги на якорі; $u_{\mathrm{H}}(t)$ та $E$ - відповідно миттєві значення вихідної напруги НПП та проти ЕРС; $a_{1}=\varepsilon_{a}+\frac{2 T_{a b}}{\Delta t}, a_{3}=\varepsilon_{\mathrm{M}}+\frac{2 T_{\mathrm{M}}}{\Delta t} ; T_{a b}$ та $T_{\mathrm{M}}-$ еле- 
Міжвідомчий науково-технічний збірник «Адаптивні системи автоматичного управління» № 2' (33) 2018 ктромагнітна та механічна постійні часу двигуна, $\Delta t$ - інтервали часу, за якими проводяться розрахунки.

Система (2) вирішується за допомогою методу припасовування 3 попереднім записом початкових умов при $t=0$ та припущеннями відносно лінійної залежності моменту опору на валу двигуна від швидкості обертання [3]. Діаграми струмів кола якоря ДПС для випадку десятизонного регулювання вихідної напруги НПП наведені на рис. 2.

Вихідний струм знаходимо з співвідношення

$$
i_{2}(t)=i_{\mathrm{H}_{k}}(t) \psi_{\mathrm{BB}}(t)
$$

Вхідні струми $i_{1}(n, j, t)$ знаходимо з виразу

$$
i_{1}(n, j, t)=\frac{i_{2}(t) \psi_{B}(j, t) \psi(n, N, t)}{k_{\mathrm{T}}},
$$

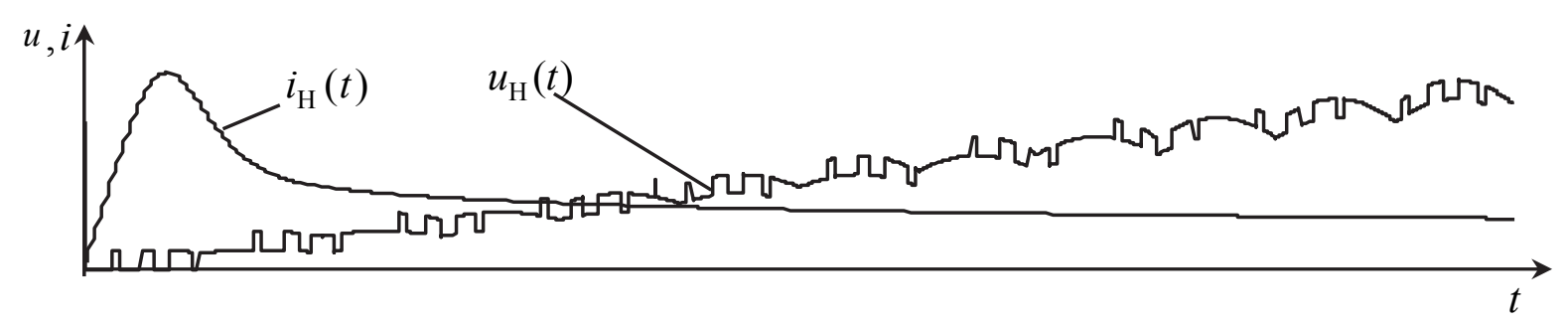

Puc. 2. Діаграми струму та напруги навантаження

Лінійні струми $i_{1}(j, t)$ знаходимо з виразу виду

$$
i_{1}(j, t)=\frac{\sum_{n=1}^{N=10} i_{\mathrm{H}}(t) \psi_{\mathrm{B} 2}(j, t) \psi_{2}(j, t) \nu_{2}(\mathrm{t})}{k_{\mathrm{T}}} .
$$

Вхідні фазні струми $i_{02}(i, t)$ знаходимо з співвідношень

$$
i_{01}(1, t)=i_{1}(1, t)-i_{1}(3, t) ; i_{01}(2, t)=i_{1}(2, t)-i_{1}(1, t) ; i_{01}(3, t)=i_{1}(3, t)-i_{1}(2, t) .
$$

Діаграми вхідних фазних струмів перетворювача в координатах напруг енергетичної мережі, побудовані за (6), представлені на рисунку 3. 

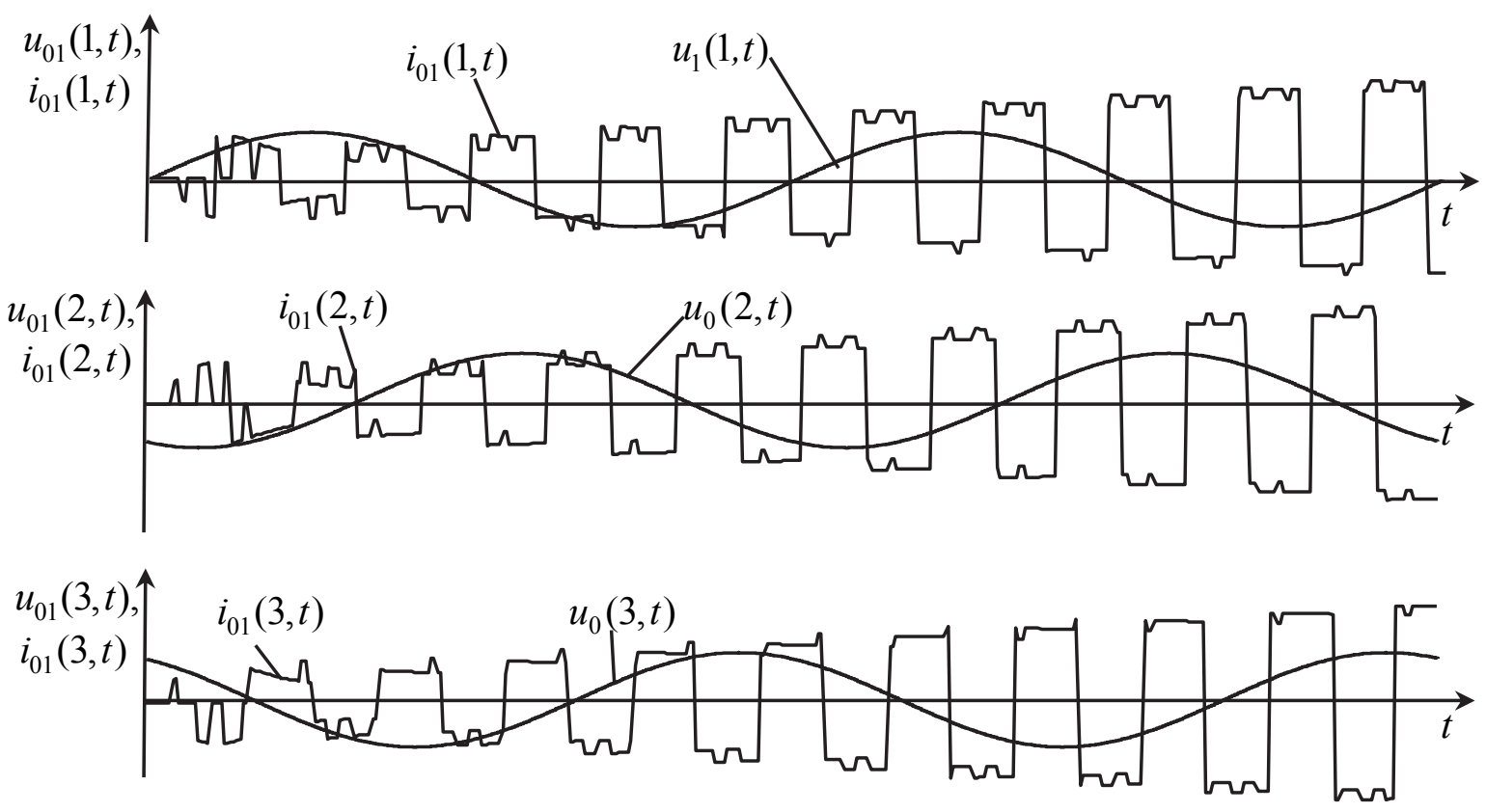

Puc. 3. Діаграми вхідних струмів $i$-х фаз мережі в координатах фазних напруг

\section{Висновки}

У данні роботі було виконано аналіз електромагнітних процесів в електричних колах 3 напівпровідниковими перетворювачами. Використовуючи метод багатопараметричних модулюючих функцій було знайдено струм i напругу навантаження, а також вхідні струми перетворювача. У роботі розвинуто метод багатопараметричних функцій в частині розробки нової математичної моделі з багатозонним регулюванням вихідної напруги і електромеханічним навантаженням та визначення модулюючих функцій для аналізу за підсистемними складовими структури електричних кіл з напівпровідниковими комутаторами.

Також формалізовано можна визначати алгоритми управління комутаторами в колах силових модуляторів фазних і лінійних напруг трифазної мережі електроживлення, що спрощує підвищення якості знакопостійних напруг у процесі формування та багатозонного регулювання вихідних синусоїдних i знакопостійних напруг. Використання багатопараметричних модулюючих функцій в математичних моделях електромагнітних процесів у електричних колах 3 напівпровідниковими комутаторами дозволяє формалізовано визначати струми в колах інверторів та інших напівпровідникових ланок кожного із силових модулів випрямлених напруг. 


\section{Список використаних джерел}

1. Макаренко М.П. Математична модель перетворювача трифазної напруги в постійну напругу / М.П. Макаренко, В.В. Михайленко // Электроника и связь. - 2002. № 14. - С. 73-75.

2. Патент 20985. України. МПК Н02М 1/02. Модулятор випрямленої напруги / М.П. Макаренко, В.В. Михайленко, Заявник та власник патенту НТУУ “КПІ” - Завл. 18.09.2006, опубл. 15.02.2007. Бюл. № 2.

3. Макаренко М. П. Системний аналіз електромагнітних процесів у напівпровідникових перетворювачах електроенергії модуляційного типу / М. П Макаренко, В.І. Сенько, М. М. Юрченко - К. : НАН України, ІЕД, 2005. - 241 с.

4. Макаренко Н. П. Анализ электромагнитных процессов в двенадцатипульсном преобразователе с зонным регулированием выходного напряжения / Н. П. Макаренко, В. В. Михайленко, Н. Н. Юрченко // Вестник НТУ "Харьковский политехнический институт". "Проблемы автоматизированного электропривода. Теория и практика". - 2002. - Т. 1. C. 233-234. 